\title{
After VITAL study: Is Vitamin D supplementation necessary?
}

\section{Rose Sakamoto* \\ Robust Aging Program, California State University Fullerton, USA}

Informing the public about Vitamin D, its benefits, particularly its protective effects against non-skeletal chronic illnesses such as that of cardiovascular and cancer effects remains challenging and confusing [1]. The recent Vitamin D and Omega-3 fatty acid (VITAL) study results, a Randomized Clinical Trial (RCT) [2] has further thrown the public in mistrusting vitamin D supplementation. I hear patients and practitioners alike stating: "vitamin D does not work" perhaps because they equate the negative findings of the VITAL study to mean that vitamin D (cholecalciferol) supplementation is not effective at all. Such misunderstanding could lead to stepping backwards from what the scientific society has long proven the science behind Vitamin D's effects. Hence, the purpose of this commentary is to discuss weaknesses in the VITAL's study that could assist healthcare practitioners' hence, the population they serve on vitamin D supplementation.

VITAL study [2] was aimed to explore whether vitamin D was protective against cancer and cardiovascular diseases. The largest randomized trial, placebo-controlled two-by-two factorial design, using vitamin D3 cholecalciferol 2000 IU daily for an average of 5.3 years. Participants were from across the United States aged $\geq 50$ years (25, 871), $20 \%$ of population were blacks and $51 \%$ women. Results showed no significant differences in incidence of cancer between the two groups: supplemented and those with placebo. Supplementation with cholecalciferol did not result in lower incidence of invasive cancer: Hazard ratio 0.96 ; $95 \%$ Confidence Interval [CI] 0.88 to $1.06 ; p=0.47$. Results also showed no significant changes in CVD diseases: Hazard ratio 0.97 ; $95 \%$ CI $0.85-1.12 ; p=0.69$.

As much as we rely on RCT being the preferred type of study for proving a drug's efficacy, inconsistencies within the study could have diluted cholecalciferol's effects. These inconsistencies of the VITAL study include amongst others: Under dosage, inadequate blood levels monitoring and confounders not well-addressed.

Participants received Vitamin D3 Cholecalciferol 2000 IU dosage which the researchers based on calculations derived from the 2008 Institute of Medicine's (IOM) recommendations. These recommendations used lower dosages because calculations were then based from the 1999 Required Dietary Allowances (RDA) which were not adequate hence, were updated in 2011 [3]. VITAL study was designed when the recommendations were at $600 \mathrm{IU}$ for adults based on studies that did not have strong evidence of cut-off levels. Manson, et. al $[2,4]$ derived their pre-trial study design planning from the Women's Health study (WHI) on vitamin D and calcium [5] that used low dosage of $400 \mathrm{IU}$ amongst other many limitations. In addition, more than half of the VITAL's participants $(15,787)$ were taking $800 \mathrm{IU}$ daily which means these participants already attained $40 \%$ of the target dose of 2000 IU. Further, towards the end of the study, outside use of vitamin D $>800$ IU was at $6.4 \%$ and $10.8 \%$ for those supplemented and placebo groups, respectively.
Serum 25(OH)D monitoring of blood levels was inadequate. Participants need to be either at insufficient or deficient levels to see effects. VITAL study participants had baseline levels within the normal levels: $30.8 \mathrm{ng} / \mathrm{ml}$, a serum D concentration that could already reduce the risk of adverse health effects. Only $12.7 \%$ of whole study participants were vitamin D deficient at baseline. Such baseline participants' conditions made it difficult to determine the possible positive effects of increased vitamin D dosage through supplementation. Serum Vitamin $\mathrm{D}$ does not respond linearly, i.e. those with good levels need more dosage to see an effect vs those with low levels as highly advised when strategizing vitamin D supplementation [6,7].

Serum 25(OH)D concentrations capture effects of many confounders e.g. sunlight exposure, season, latitude, and lifestyle changes that must be controlled. Control of such confounders was not clearly stated in the VITAL study. Also, blood levels usually depict effects more accurately if serum D levels are measured near or at the time of the health effects are determined [6].

VITAL study although an RCT showed many weaknesses in its methodology- an incomplete picture [8] that deciphered what dosage was enough to effect changes rather than the primary endpoints [9]. Cholecalciferol should be considered more than just a vitamin D supplementation but foremost, a nutrient replenishment [10]. Therefore, it is imperative to continue to mitigate vitamin D deficiency, a pandemic public health concern if not with sunlight [11], with vitamin D supplementation as per current guidelines [12].

\section{References}

1. Minisola S, Ferrone F, Danese V, Cecchetti V, Pepe J, et al. (2019) Controversies Surrounding Vitamin D: Focus on Supplementation and Cancer. Int $J$ Environ Res Public Health 16: E189. [Crossref]

2. Manson JE, Cook NR, Lee IM, Christen W, Bassuk SS, et al. (2019) Vitamin D Supplements and Prevention of Cancer and Cardiovascular Disease. N Engl J Med 380: 33-44. [Crossref]

3. Ross A, Taylor C, Yaktine Al, Del Valle HB, (2011) IOM, Dietary Reference Intakes for Vitamin D and Calcium Dietary reference intakes for calcium and vitamin D Washington, D.C.: The National Academies Press.

4. Manson JE, Cook NR, Lee IM, Christen W, Bassuk SS, et al. (2019) Marine n-3 Fatty Acids and Prevention of Cardiovascular Disease and Cancer. N Engl J Med 380: 23-32. [Crossref]

5. LaCroix AZ, Kotchen J, Anderson G, Brzyski R, Cauley JA, et al. (2009) Calcium plus vitamin D supplementation and mortality in postmenopausal women: The Women's Health Initiative calcium-vitamin D randomized controlled trial. J Gerontol A Biol Sci Med Sci 64: 559-567. [Crossref]

*Correspondence to: Rose Sakamoto, Robust Aging Program, School of Nursing, California State University Fullerton, USA, Tel: 657-278-7649; E-mail: rsakamoto@Fullerton.edu

Received: September 01, 2019; Accepted: September 16, 2019; Published: September 20, 2019 
6. Grant WB, Boucher BJ, Bhattoa HP, Lahore H (2018) Why vitamin D clinical trials should be based on 25-hydroxyvitamin D concentrations. J Steroid Biochem Mol Biol 177: 266-269 [Crossref]

7. Landel V, Annweiler C, Millet P, Morello M, Féron F (2016) Vitamin D, Cognition and Alzheimer's Disease: The Therapeutic Benefit is in the D-Tails. J Alzheimers Dis 53 419-444. [Crossref]

8. Infante M, Ricordi C, Baidal DA, Alejandro R, Lanzoni G, et al. (2019) VITAL study: an incomplete picture? Eur Rev Med Pharmacol Sci 23: 3142-3147. [Crossref]
9. William Grant (2019) Vitamin D Reduces Cancer Risk: Why Scientists Accept It but Physicians Do Not. Orthomedicine News Release

10. Heaney RP (2014) Guidelines for optimizing design and analysis of clinical studies of nutrient effects. Nutr Rev 72: 48-54. [Crossref]

11. Sakamoto, RR (2019) Sunlight in Vitamin D Deficiency: Clinical Implications. JNP 15: 282-285.

12. Pludowski P, Holick MF, Grant WB, Konstantynowicz J, Mascarenhas MR, et al (2018) Vitamin D supplementation guidelines. J Steroid Biochem Mol Biol 175: 125 135. [Crossref]

Copyright: C2019 Sakamoto R. This is an open-access article distributed under the terms of the Creative Commons Attribution License, which permits unrestricted use, distribution, and reproduction in any medium, provided the original author and source are credited. 